\title{
Synthesis of Moderate Water-Uptake and Low Methanol Permeable Polymer Electrolyte Membrane from Functionalized Polyisoprene Impregnated Carbon Nanotubes
}

\author{
Christopher A. Idibie \\ Department of Chemical Sciences, Faculty of Science, Edwin Clark University, Kiagbodo, Nigeria
}

Email address:

krisid2007@yahoo.com

To cite this article:

Christopher A. Idibie. Synthesis of Moderate Water-Uptake and Low Methanol Permeable Polymer Electrolyte Membrane from Functionalized Polyisoprene Impregnated Carbon Nanotubes. International Journal of Materials Science and Applications. Vol. 7, No. 1, 2018, pp. 6-12. doi: 10.11648/j.ijmsa.20180701.12

Received: October 16, 2017; Accepted: December 7, 2017; Published: January 2, 2018

\begin{abstract}
The study of the synthesis of polymer electrolyte membrane exhibiting moderate water uptake and low methanol permeation for fuel cell application using functionalized polyisoprene impregnated with carbon nanotubes (CNTs) was carried out. The functionalization of the polymer with chlorosulphonic acid of different initial concentrations of $0.0013,0.001,0.0017$, and $0.0023 \mathrm{~mol} / \mathrm{L}$ at the minimum time of $1 \mathrm{hr}$ produced ion exchange capacities (IEC) of $1.22,1.92,2.74$, and $4.92 \mathrm{mmol} / \mathrm{g}$, respectively, and at the maximum sulphonation time of $18 \mathrm{hrs}$ the IEC were $7.74,8.78,11.10$, and $16.93 \mathrm{mmol} / \mathrm{g}$, respectively. Their corresponding degrees of sulphonation (DS) for $1 \mathrm{hr}$ were $3.53,5.55,7.91$, and $14.21 \%$, respectively, and while at $18 \mathrm{hrs}$ their corresponding DS were $22.35,25.37,32.04$, and $48.88 \%$, respectively, which implies that IEC and DS are directly proportional to the concentration of acid used and reaction time. Result also showed that synthesized membrane without carbon nanotubes absorbed so much of it weight in water; 31.34 and $73.97 \%$ of its weight in both 1 day and 6 days for membrane with $48.88 \%$ DS. Whereas the membrane that was impregnated with CNTs of the same DS exhibited a lesser absorption of 23.23 and $53.23 \%$ of its weight in both 1 day and 6 days, thereby reducing the high water uptake of the membrane that would have affected it negatively by 1.3 fold. Apart from the conductivity of the synthesized membrane witnessing an increase by 1 order with the membrane impregnated with CNTs from $10^{-3} \mathrm{~S} / \mathrm{cm}$ to $10^{-2} \mathrm{~S} / \mathrm{cm}$, it was also found out that the methanol crossover was lower than that of commercial Nafion, where membrane impregnated with CNTs had methanol crossover improvement with a difference of $0.48 \mathrm{Mol} / \mathrm{L}$ over its counterpart without CNTs as a result of the presence of CNTs.
\end{abstract}

Keywords: Polymer Electrolyte Membrane, Polyisoprene, Chlorosulphonic Acid, Ion Exchange Capacity, Degree of Sulphonation

\section{Introduction}

Fuel cells which are recognized as viable and promising alternative energy sources to fossil fuel $[1,2]$ require the central component being the polymer electrolyte membrane (PEM) to function $[3,4]$. Water molecules are necessary in the membrane because it provides the medium for the movement of ions, but excess uptake of water results in swelling of the membrane and which consequently, affect the mechanical and conductivity properties [5]. In another vein, methanol permeation through polymer electrolyte membrane (PEM) is recognized as a major problem and constraint against large scale commercialization of fuel cell, especially direct methanol fuel cell (DMFC) for energy generation [5] Fuel cells such as proton exchange membrane fuel cell (PEMFC) or direct methanol fuel cell (DMFC) are known to have proton-conducting pathways produced by fixed functional groups or proton conducting gel [6]. 
At present, Nafion a perfluorosulfonic acid polymer which most PEMFC and DMFCs operate is the state-of-the art PEM for fuel cells. It is expected that such a polymer electrolyte membrane should have low fuel (methanol) permeability together with good ion conductivity [6], but in contrast it has the problem of permeability to methanol [7]. Comparing the likes of DMFCs to the conventional $\mathrm{H}_{2} / \mathrm{O}_{2}$ fuel cell, DMFCs in particular are attractive for several applications as a result of their lower weight and volume compared with indirect fuel cells; however the major challenge associated with it is the loss of fuel due to the permeation of methanol across the Nafion membrane [8]. It is recognized that this large methanol permeability does not only cause the mixed potential phenomena by increasing the over potential of the cathode thereby reducing cell performance, but also lowers the fuel efficiency $[5,9]$. Research in the field of fuel cell is therefore geared towards the preparation and testing of membranes with moderate water uptake ability alongside low methanol crossover that will be cost effective unlike that of Nafion that is way very expensive $[7,10,11]$. While several ionomers that are relatively of low cost have been studied because of their morphologies arising from their structural combination of both hydrocarbon block and ionomer block $[12,13,14,15]$, study of stable aromatic polymers such as poly(ether ether ketone) [16], polyethersulfone [17, 18], polyamide [19] and poly (phenylene sulphide) [20] as well as composite membranes [21,22] have also been carried out in a bid to getting an alternative that shows characteristic of overcoming the challenge of fuel oxidation due to methanol crossover effect, yet the problem of methanol crossover persists [5]. In this work therefore, effort to functionalize polyisoprene through sulphonation and impregnation of carbon nanotubes (CNTs) will be carried out and study for its water absorption and methanol crossover abilities, in an effort of getting an alternative PEM.

\section{Experimental}

\subsection{Materials and Equipment}

Chemicals used in this work are of analytical grade. Among them are: Toluene, chlorosulphonic acid, ethanol (Charlec, Nigeria), commercial polyisoprene (Karbochem RSA) and Carbon nanotubes (Wits RSA), distilled/deionised water (Edwin Clark University) and a fabricated four neck reactor.

\subsection{Functionalization of Polyisoprene Using Chlorosulphonic Acid}

This process was achieved according to the method described by Idibie et al [5], although with slight modification Following a batch process, polyisoprene $(15 \mathrm{~g})$ was dissolved in a beaker using $300 \mathrm{ml}$ toluene reagent, and which was accompanied with the gradual addition of concentrated chlorosulphonic acid of different initial concentrations of $0.0013,0.0015,0.0017$ and $0.0023 \mathrm{~mol} / \mathrm{L}$, respectively that was initially chilled in an iced bath, to the solution mixture of toluene and the polyisoprene (PI) undergoing a vigorous stirring in a four-neck round bottom flask reactor. This was done under argon atmosphere at room temperature. The sulphonation reaction was allowed to proceed at different times of 1, 3, 6, 9, 9, 12, 15 and 18 hours, respectively and was terminated with the addition of ethanol. The precipitated sulphonated PI (SPI) was recovered and washed with deionised water until 6-7 $\mathrm{pH}$ of wash was reached. This was followed by drying the SPI in an oven at $80^{\circ} \mathrm{C}$ for a period of $2-3$ hours.

\subsection{Impregnation of Carbon Nanotubes into Sulphonated Polyisoprene}

In this process, carbon nanotubes (CNTs) (1.2 g) was first functionalised by dissolving it in a solution of sulphuric acid and later introduced into a solution of previously dried SPI that was dissolved in a $150 \mathrm{ml}$ toluene that was equipped with a magnetic stirrer, in a four-neck round bottom flask reactor. This was done under an argon atmosphere at room temperature. The reaction was allowed to proceed for a period of 5 hours, such that, the carbon nanotubes mixed thoroughly and well enough inside the matrix of the sulphonated polymer (SPI). At the end of the reaction the viscose dark solution was cast into a thin film.

\subsection{Membrane Fabrication into Thin Films}

Using a laboratory doctor blade casting machine set at appropriate thickness with the aid of feeler gauges, casting of sulphonated polyisoprene (SPI) and sulphonated polyisoprene impregnated with carbon nanotubes (SPICNTs) into a thin membrane was carried out according to the method described by Idibie et al [5]. Here, both SPI and SPICNTs were dissolved in $150 \mathrm{ml}$ of toluene at elevated temperature to form a casting solution, and thereafter cast onto a clean polymer paper support. The casting process involves drawing the casting head of the blade along the length of the substrate, and allowed to cure for 5 days by exposing it to air, and later ovum dried below $80^{\circ} \mathrm{C}$ for about 3 hours. To remove any trace of residual solvent the cast membrane was vacuum dried for 2 hours.

\subsection{Ion Exchange Capacity and Degree of Sulphonation Determination}

In determining the Ion Exchange Capacity (IEC) and Degree of Sulphonation (DS) of the Sulphonated PI (SPI), the percentages of sulphur in the dry samples of SPI were measured via the method of elemental analysis and thus the IEC was calculated using Equation (1) [23]:

$$
\mathrm{IEC}=\frac{1000 \mathrm{~S}_{\mathrm{c}}}{\mathrm{MW}_{\mathrm{s}}}
$$

where: $\mathrm{S}_{\mathrm{c}}$, and $\mathrm{MW}_{\mathrm{s}}$, denote the sulphur content in percentage weight rate and the molecular weight of sulphur and, 1000 is the multiplication factor to have IEC value in $\mathrm{mmol} / \mathrm{g}$.

The values of IEC obtained using Equation 1 was thus 
used to determine the degree of sulphonation of SPI according to Equation (2) [24]:

$$
\mathrm{DS}=100 \times\left(\frac{\mathrm{MW}_{\mathrm{SPI}} \times \mathrm{IEC}}{\mathrm{MW}_{\mathrm{PI}} \times \mathrm{MW}_{\mathrm{OSO}_{2} \mathrm{H}}}\right)
$$

where: $\mathrm{MW}_{\mathrm{SPI}}$, IEC, $\mathrm{MW}_{\mathrm{PI}}$ and $\mathrm{MW}_{\mathrm{OSO}_{2} \mathrm{H}}$ denote the molecular weight of the sulphonated polyisoprene, the ion exchange capacity, the molecular weight of unsulphonated polyisoprene and the molecular weight of $\mathrm{OSO}_{2} \mathrm{H}$.

\subsection{Hydro Properties of Synthesized Membrane}

To determine the water uptake ability of the synthesised membrane, different membranes of known weights and dimensions were immersed in distilled water for a few days until they became saturated. The water uptake was thus determined from the weight difference between the wet and dry membranes according to Equation (3) [7]

$$
\text { Water uptake }(\%)=\frac{W_{w e t}-W_{d r y}}{W_{d r y}} \times 100
$$

where: $W_{\text {wet }}$ and $W_{d r y}$ represent weights $(g)$ of the wet membranes and dry membranes, respectively.

The membrane swelling ratio was determined using Equation (4), as:

$$
\frac{T_{w e t}-T_{d r y}}{T_{d r y}} \times 100
$$

where: $T_{\text {wet }}$ and $T_{d r y}$ represents the thickness of both the wet and dry membranes.

\subsection{Measurement of Ionic Property}

Measurement of the proton conductivity of the synthesized membrane was achieved by using alternating current impedance over a frequency range of $1-10^{6} \mathrm{~Hz}$ in $1 \mathrm{M} \mathrm{H}_{2} \mathrm{SO}_{4}$ as an electrolyte. The intersection value of the high frequency impedance curve was taken as the membrane resistance and thus the proton conductivity was calculated according to Equation (5):

$$
\sigma=\frac{T}{R S}
$$

where: $\sigma$ denotes proton conductivity $(\mathrm{S} / \mathrm{cm}), T(\mathrm{~cm})$ is the thickness, $S\left(\mathrm{~cm}^{2}\right)$ is the surface area of the membrane and $R$ is the resistance determined from the impedance plane.

\subsection{Measurement of Methanol Permeability}

Methanol permeability also known as crossover through the synthesised membranes was measured in two identical chamber containers. This involves the use of membrane of known degree of sulphonation and thickness with surface area of $6.539 \mathrm{~cm}^{2}$ that was placed between identical chambers of volume $65 \mathrm{~cm}^{3}$. While one of the chambers contains concentrated methanol the second chamber contains water, and the contents in the two chambers were well stirred with a magnetic stirrer for homogeneity. A small amount of the solution was taken from the second chamber at different times to determine the concentration of methanol that crossed over or diffused through. This followed by measuring the methanol concentration in the water chamber with the help of a UV spectroscopy of 4802 UV/VIS model.

\section{Results}

\subsection{Reaction Scheme}

Below reaction scheme represents the reaction of polyisoprene in chlorosulphonic acid medium.

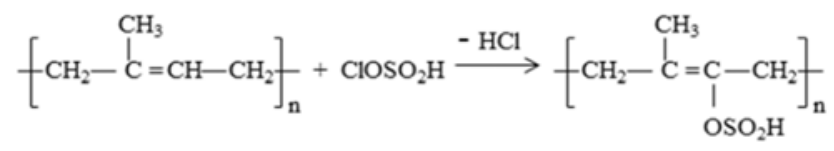

Scheme 1. Reaction of polyisoprene in chlorosulphonic acid medium [25].

\subsection{Figures}

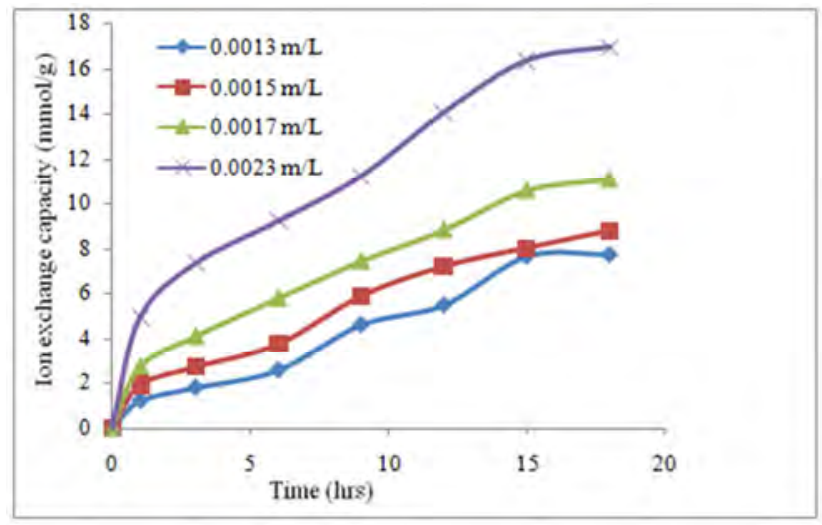

Figure 1. A plot of ion exchange capacity against time.

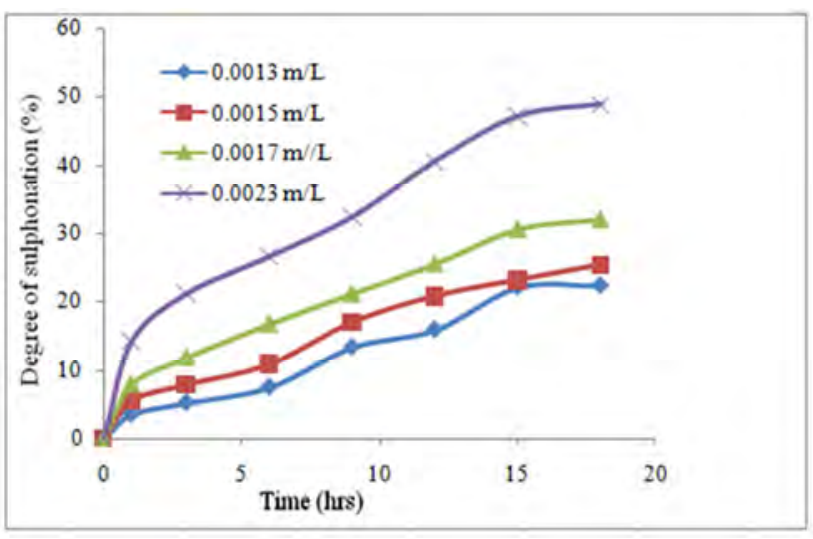

Figure 2. A plot of degree of sulphonation against time. 


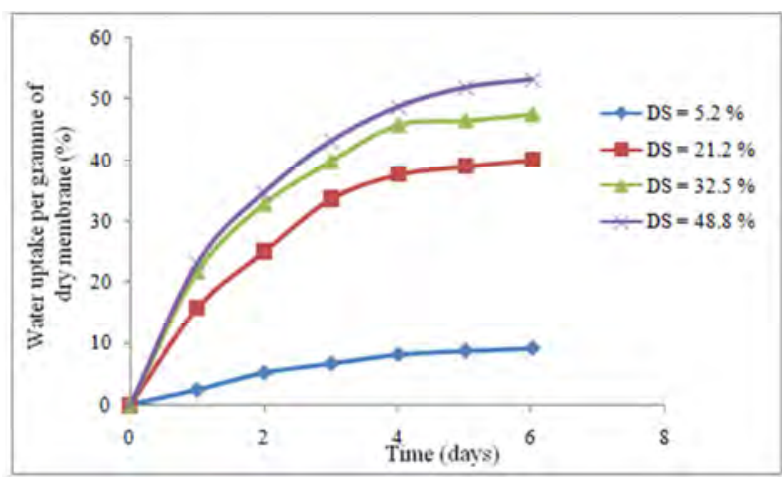

Figure 3. Water uptake capacity as a function of time and degree of sulphonation.

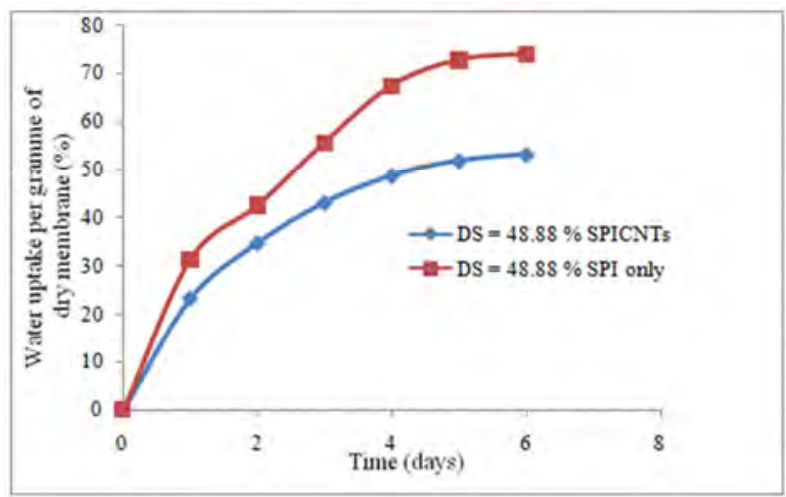

Figure 4. Comparison of water uptake between membrane with and without carbon nanotubes.

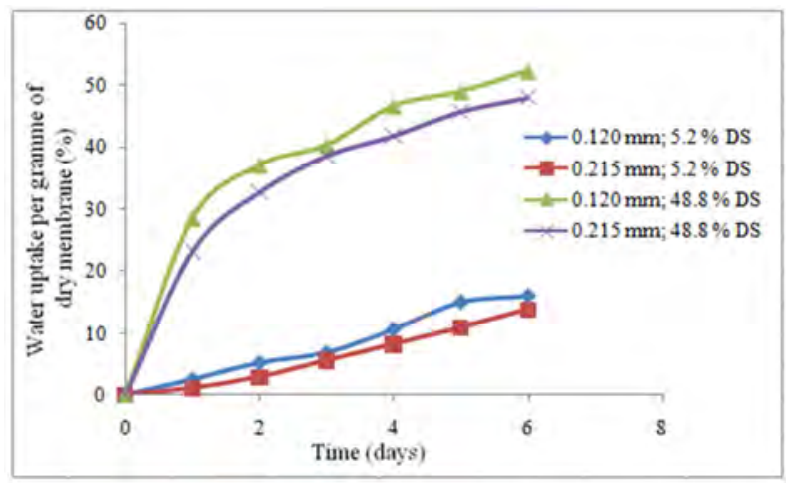

Figure 5. Water uptake of membrane versus time with different membrane thickness.

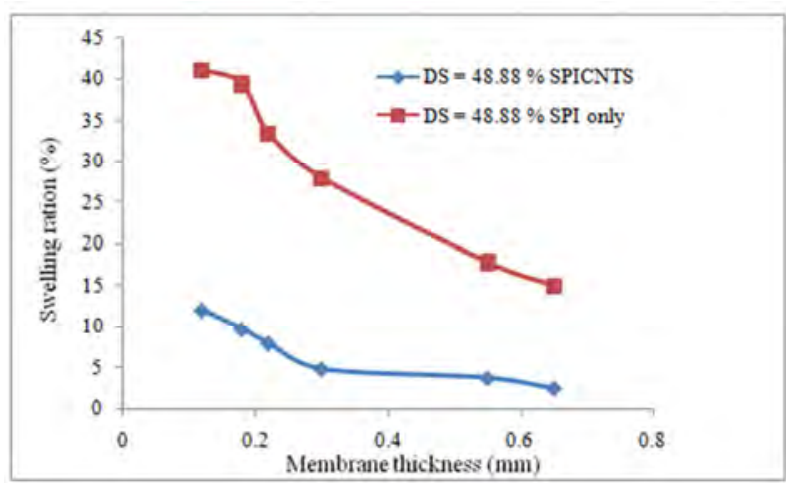

Figure 6. Membrane swelling ration versus membrane thickness for both membranes with and without carbonnanotubes.

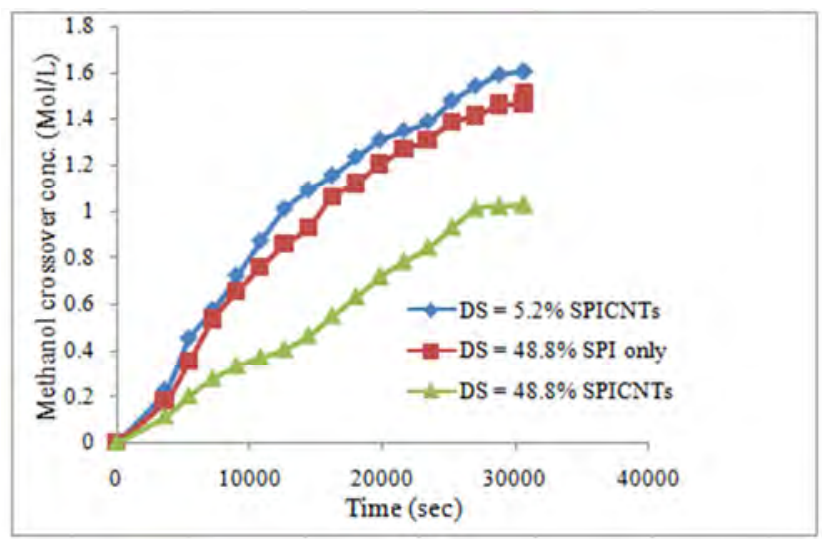

Figure 7. Methanol crossover concentration at different degrees of sulphonation with and without carbon nanotubes.

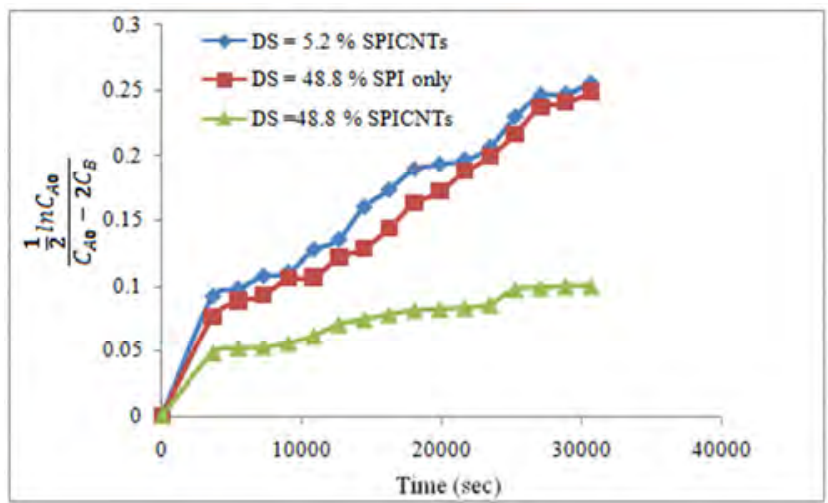

Figure 8. Plot of $\frac{\frac{1}{2} \ln C_{A 0}}{C_{A 0}-2 C_{B}}$ against time at different degree of sulphonation.

\subsection{Tables}

Table 1. Conductivity as a function of DS at different membrane thickness.

\begin{tabular}{llll}
\hline DS (\%) & $\begin{array}{l}\text { 0.120 mm } \\
\text { Without CNTs }\end{array}$ & $\begin{array}{l}\text { 0.215 mm } \\
\text { Without CNTs }\end{array}$ & $\begin{array}{l}\text { 0.215 mm With } \\
\text { CNTs }\end{array}$ \\
\hline 7.9 & $4.11 \times 10^{-3} \mathrm{~S} / \mathrm{cm}$ & $2.78 \times 10^{-3} \mathrm{~S} / \mathrm{cm}$ & $4.87 \times 10^{-3} \mathrm{~S} / \mathrm{cm}$ \\
13.3 & $4.92 \times 10^{-3} \mathrm{~S} / \mathrm{cm}$ & $2.97 \times 10^{-3} \mathrm{~S} / \mathrm{cm}$ & $9.23 \times 10^{-3} \mathrm{~S} / \mathrm{cm}$ \\
32.42 & $6.63 \times 10^{-3} \mathrm{~S} / \mathrm{cm}$ & $3.17 \times 10^{-3} \mathrm{~S} / \mathrm{cm}$ & $1.25 \times 10^{-2} \mathrm{~S} / \mathrm{cm}$ \\
40.6 & $8.11 \times 10^{-3} \mathrm{~S} / \mathrm{cm}$ & $5.40 \times 10^{-3} \mathrm{~S} / \mathrm{cm}$ & $2.52 \times 10^{-2} \mathrm{~S} / \mathrm{cm}$ \\
48.8 & $9.85 \times 10^{-3} \mathrm{~S} / \mathrm{cm}$ & $6.79 \times 10^{-3} \mathrm{~S} / \mathrm{cm}$ & $3.29 \times 10^{-2} \mathrm{~S} / \mathrm{cm}$ \\
\hline
\end{tabular}

Table 2. Overall diffusion coefficient of synthesized membrane.

\begin{tabular}{lll}
\hline \multirow{2}{*}{ DS (\%) } & \multicolumn{2}{l}{ Membrane thickness $(\mathbf{m m})$} \\
\cline { 2 - 3 } & $\mathbf{0 . 1 2 0}$ & $\mathbf{0 . 2 1 5}$ \\
\hline 5.2 without CNTs & $4.6 \times 10^{-8}$ & $5.2 \times 10^{-8}$ \\
48.88 without CNTs & $3.1 \times 10^{-8}$ & $3.2 \times 10^{-8}$ \\
48.88 with CNTs & $2.8 \times 10^{-8}$ & $3.0 \times 10^{-8}$ \\
\hline
\end{tabular}

\section{Discussion}

\subsection{Ion Exchange and Degree of Sulphonation}

Generally the ion exchange capacity of a membrane is regarded as a function of the membrane's acid concentration which is brought about by interaction of the acid and the polymer via sulphonation as shown in reaction scheme 1 . Thus the acid concentration of the membrane is associated 
with the amount of ionic groups present in the membrane and which is referred to as the measure of the degree of sulphonation (DS) [26]. Hence the IEC becomes an indicator of the proton conduction sites $[27,28]$ and a function of the proton conductivity. Results of both IEC and DS showed that they were function of time and concentration of acid used, as higher the time and concentration of the acid the higher the IEC and DS. From Figure 1 while the IEC at minimum sulphonation time of $1 \mathrm{hr}$ for the different initial concentrations of acid of $0.0013,0.001,0.0017$, and 0.0023 $\mathrm{mol} / \mathrm{L}$ were $1.22,1.92,2.74$, and $4.92 \mathrm{mmol} / \mathrm{g}$, respectively, and at the maximum sulphonation time of $18 \mathrm{hrs}$ the IEC were $7.74,8.78,11.10$, and $16.93 \mathrm{mmol} / \mathrm{g}$, respectively. Their corresponding DS as shown in Figure 2 showed that at $1 \mathrm{hr}$, the DS were $3.53,5.55,7.91$, and $14.21 \%$, respectively, while at $18 \mathrm{hrs}$ their corresponding DS were $22.35,25.37,32.04$, and $48.88 \%$, respectively.

\subsection{Hydro Properties of Synthesized Membrane}

Water molecules in the membrane are very vital for the membrane to function ideally as a proton exchange membrane because it provides the medium for the movement of ions, although excess uptake of water is disadvantageous as it results in swelling of the membrane, which consequently affect the mechanical and conductivity properties of the membrane. Results in Figure 3 showed that water uptake is directly proportional to the DS as the membrane with the lowest DS $(5.22 \%)$ was able to absorb 2.45 and $9.23 \%$ of its weight in water at both 1 day and 6 days, whereas membrane with the highest DS (48.88\%) absorbed so much of it weight in water, as it absorbed 31.34 and $73.97 \%$ of its weight in both 1 day and 6 days. It is interesting to note however, that the membrane that was impregnated with CNTs of the same DS (48.88\%) as shown in Figure 4 was only able to absorb 23.23 and $53.23 \%$ of its weight in both 1 day and 6 days and thereby reducing the high water uptake of the membrane that would have affected it negatively by a 1.3 fold. This is an improvement on the original membrane synthesized from ordinary polyisoprene polymer without CNTs. On the effect of membrane thickness on water absorption ability of the synthesized membrane, result presented in Figure 5 showed that water uptake has an inverse relationship with the membrane thickness as smaller the thickness of the membrane the more the membrane absorbed water. At constant DS of $5.2 \%$ membrane of $0.120 \mathrm{~mm}$ absorbed more water than that of $0.215 \mathrm{~mm}$, and at constant DS of $48.8 \%$ membrane of $0.120 \mathrm{~mm}$ absorbed higher water than that of $0.215 \mathrm{~mm}$. Also, same inverse trend is noticed on the membrane swelling ratio and membrane thickness. Comparatively however, While swelling ratio for membrane with the smallest thickness $(0.120 \mathrm{~mm})$ without CNTs was $41.01 \%$ the membrane with CNTs impregnated was just $12 \%$, thereby achieving a swelling ratio reduction that is $>3$ fold, the membrane of a higher thickness $(0.65 \mathrm{~mm})$ without carbon CNTs was $15.03 \%$ while with CNTs was $2.45 \%$, thereby attaining a 6 -fold reduction in swelling ratio.

\subsection{Result of Ionic Property of Synthesized Membrane}

Table 1 above presents the conductivity of the synthesized membrane as a function of DS at different membrane thickness. Results show that conductivity of the synthesized membrane increases with increase in DS and decrease in membrane thickness, as membrane without CNTs with the least DS of $7.9 \%$ and thickness of $0.120 \mathrm{~mm}$ exhibited a conductivity of $4.11 \times 10^{-3} \mathrm{~S} / \mathrm{cm}$, membrane of $0.215 \mathrm{~mm}$ of the same DS exhibited a conductivity of $2.78 \times 10^{-3} \mathrm{~S} / \mathrm{cm}$, and membrane that is impregnated with CNTs of the same DS exhibited the highest conductivity of $4.87 \times 10^{-3} \mathrm{~S} / \mathrm{cm}$. Meanwhile membrane without CNTs with the highest DS of $48.8 \%$ and thickness of $0.120 \mathrm{~mm}$ exhibited a conductivity of $9.85 \times 10^{-3} \mathrm{~S} / \mathrm{cm}$, whereas membrane of $0.215 \mathrm{~mm}$ of the same DS exhibited a conductivity of $6.79 \times 10^{-3} \mathrm{~S} / \mathrm{cm}$, and interesting to note that membrane that was impregnated with CNTs of the same DS exhibited the highest conductivity of $3.29 \times 10^{-2} \mathrm{~S} / \mathrm{cm}$, where conductivity increased by 1 order.

\subsection{Methanol Permeability}

The relation developed by Shen et al [29] has been used to determine the methanol permeation based on the following assumptions:

i Methanol solution diffusing through the membrane obeys Fick's law.

ii Equilibrium exists at methanol solutions at both sides of the membrane due to stirring.

iii There is proportional relationship between methanol concentration of bulk solution and membrane wall in contact with the solution.

Based on the assumptions stated above, diffusion due to a concentration difference across membrane, results in methanol diffusion from compartment $A$ to $B$ since $C_{A}>C_{B}$. Therefore, methanol permeation is obtained with the methanol concentration in compartment $\mathrm{B}$ with relation to time using Equation (6) [29].

$$
\frac{d C_{B}}{d t}=A_{m} \frac{\mathfrak{g}_{A m} K^{m}}{d_{m} V_{0}}\left(C_{A 0}-C_{B}\right)
$$

where: $C_{A}$ denotes the concentration of methanol in compartment $A$ and $C_{B}$ the concentration of methanol in compartment $\mathrm{B}$. $\mathrm{Vo}_{\mathrm{O}}=\mathrm{V}_{\mathrm{A}}+\mathrm{V}_{\mathrm{B}}$, and where $\mathrm{V}_{\mathrm{A}}$ and $\mathrm{V}_{\mathrm{B}}$ are the methanol volume in compartment $A$ and $B$, respectively, $A_{m}$ is the area of the membrane while $d_{m}$ represents the membrane thickness.

Figure 7 presents the concentration of methanol $(\mathrm{Mol} / \mathrm{L})$ that crossover as a function of time as methanol cross over increases with time but decreases with DS. The result showed that the membrane of DS $5.22 \%$ at the highest time $(30660$ $\mathrm{sec}$ ) crossover methanol of $1.60 \mathrm{Mol} / \mathrm{L}$ and at DS $48.88 \%$ membrane with CNTs was able to crossover methanol of 1.02 $\mathrm{Mol} / \mathrm{L}$ whereas the amount of methanol that crossover with the membrane without of CNTs of the same DS (48.88\%) was $1.50 \mathrm{Mol} / \mathrm{L}$, leaving a significant improvement difference of $0.48 \mathrm{Mol} / \mathrm{L}$ as a result of the presence of CNTs. Integrating Equation (6) above, the relationship between 
changes in concentration as a function of time was obtained thus:

$$
\frac{\frac{1}{2} l n C_{A 0}}{C_{A 0}-2 C_{B}}=A_{m} \frac{\boldsymbol{\rho}_{A m} K^{m}}{d_{m} V_{0}} t
$$

Where: $\boldsymbol{\rho}_{\mathrm{Am}}$ denotes the diffusion coefficient, $\mathrm{K}^{\mathrm{m}}$ is the Proportional constant and $\boldsymbol{\rho}_{m} \mathrm{~K}^{\mathrm{m}}$ represents the overall methanol diffusion coefficient. The slope of the plot of $\frac{\frac{1}{2} \ln _{\mathrm{A} 0}}{\mathrm{C}_{\mathrm{A} 0}-2 \mathrm{C}_{\mathrm{B}}}$ against time as presented in Figure 8 is equal to $A_{m} \frac{\boldsymbol{g}_{A m} K^{m}}{d_{m} V_{0}}$. The overall diffusion coefficient of the synthesized membrane was then determined from the slope.

The effects of degree of sulphonation (DS) on the measure of overall diffusion coefficients of the synthesised membrane at different membrane thickness are presented in Table 2. The results showed that the synthesised membrane exhibited lower methanol diffusion coefficient compared with Nafion $117\left(3.42 \times 10^{-6} \mathrm{~cm}^{2} / \mathrm{s}\right)[29]$. The result showed that methanol diffusion coefficient was higher with membrane with lower DS and also higher with membrane of $0.215 \mathrm{~mm}$. However membrane impregnated with CNTs showed a reduced overall diffusion coefficient than membrane without CNTs of the same DS.

\section{Conclusion}

Synthesis of polymer electrolyte membrane exhibiting moderate water uptake and low methanol permeation for fuel cell application was possible from functionalized polyisoprene that was impregnated with carnbon nanotubes. Study showed that there was reduction in the high water uptake of the membrane that would have affected it negatively by a 1.3 fold due to the presence of the carbon nanotubes. Apart from the conductivity of the membrane witnessing an increase by 1 order, it was also found out that the methanol crossover was lower than that of Nafion, where membrane impregnated with CNTs had methanol crossover improvement with a difference of $0.48 \mathrm{Mol} / \mathrm{L}$ over its counterpart without CNTs as a result of the presence of CNTs.

\section{Acknowledgements}

University of the Witwatersrand, Johannesburg, South Africa for their financial and material assistance.

\section{References}

[1] Wonbong, J, L. Choonkeun, S. Saimani, G. S. Yong, and H. Haksoo (2005). Thermal and hydrolytic stability of sulfonated polymide membranes with varying chemical structure. Polymer degradation and Stability 90, 431-440.

[2] L. Xianguo, "Principles of fuel cells", New York: Taylor and Francis group LLC, 2006, pp. 1-147.
[3] Bai, Y, C. Wu, F. Wu, and B. Yi (2006). Carbon-supported platinum catalysts for onsite hydrogen generation from $\mathrm{NaBH}_{4}$ solution. Material letter, 60, 2236 - 2239.

[4] Costamagna, P, S. Srinivasan (2001). Quantum jumps in the PEMFC science and technology from the 1960s to the year 2000. Part 1. Fundamental scientific aspect. Journal of Power Source, 102, 242-252.

[5] Idibie, C. A, A. S. Abdulkareem, H. C. Vz. Pienaar, S. E Iyuke, and D. L. Van (2009). Synthesis of low methanol permeation polymer electrolyte membrane from polystyrenebutadiene rubber. Polymer-Plastics Technology and Engineering, 48, $1121-1129$.

[6] Yo, J. K, C. C. Won, I. W. Seong, H. H. Won (2004). Proton conductivity and methanol permeation in Nafion ${ }^{\mathrm{TM}} /$ ORMOSIL prepared with various organic silanes. Journal of Membrane Science, 238, 213-222.

[7] Gao, Y, P. R. Gilles, M. D. Guiver, X. Jian, S. D. Mikhailenko, K. S. Wang (2003). Sulfonation of poly (phthalazinones) with fuming sulfuric acid mixtures for proton exchange membrane materials. Journal of Membrane Science, $227,39-50$.

[8] Walker, M, K. M. Baumgartner, M. Kaiser, J. Kerres, A. Ullrich, E. Rauchle (1999). Proton-conducting polymers with reduced methanol permeation. Journal of Applied Polymer Science, 74, 67-73.

[9] Hikita, S, K. Yamane, Y. Nakajima (2001). Measurement of methanol crossover in direct methanol fuel cell. Japan society of Automotive Engineers Review, 22, 151-156.

[10] Savadogo, O. and J. N. Mater (1998). Emerging membranes for electrochemical systems: (1) solid polymer electrolyte membrane for fuel cell systems. Electrochemical Systems, 1, $47-66$

[11] Inzelt, M, M. Pineri, J. W. Schltze, and M. A. Vorotyntsev (2000). Electron and proton conducting polymers: recent development and prospects. Electrochemical Acta, 45, 2403.

[12] Gautthier, S. and A. Eisenberg (1987). Vinylpyridinum ionmers. 2. Styrene-based ABA block copolymer. Macromolecules, 20, 760-767.

[13] Zhou, Z, D. Peifer, and B. Chu (1994). Light scattering studies of block ionomer aggregation characteristics in nonplar solvent. Macromolecules, 27, 1428-1433.

[14] Desjardins, A, and A. Eisenberg, (1991). Colloidal properties of block ionomers.1. Characterization of reverse micelles of styrene-b-metal methacrylate diblocks by size-exclusion chromatography. Macromolecules, 24, 5779-5790.

[15] Weiss, R. A, A. Sen, L. A. Pottik, and C. L. Willis (1990). Block copolymer ionomers. Thermoplastic elastomers possessing two distinct physical networks. Polymer Communication, 31, 220-223.

[16] Wang, F, J. Li, T. Chen, J. Xu (1998). Sodium sulfonatefunctionalised poly (ether ether ketone)s. Macromolecular Chemistry and Physics, 199, 1421-1426.

[17] Ueda, M, H. Toyota, T. Ouchi, J. Sugiyama, K. Yonetake (1993). Synthesis and characterization of aromatic poly (ether sulfone)s containing pendant sodium sulfonate groups. Journal of Polymer Science, 31, 853-858. 
[18] Wang, F, M. Hickner, J. E. Mcgrath (2002). Direct polymerization of sulfonated poly (arylene ether sulfone) random (statistical) copolymers: Candidates for new proton exchange membranes. Journal of Membrane Science 197, 231-242.

[19] Genies, C, R. Mercier, B. Sillion, N. Cornet, G. Gebel, M. Pineri (2001). Soluble sulfonated naphthalenic polyimides as materials for proton exchange membranes. Polyer, 42, 359373.

[20] Allam, C, K. J. Liu, D. Mohanty (1999). Preparation and properties of novel aromatic poly (thioethers) derived from 4,40-thiobisbnzenethiol. Macromolecular of Chemistry and Physics, 200, 1854-1862.

[21] Honma, I, S. Nomura, H. Nakajima (2001). Proton conducting organic/inorganic nanocomposite for polymer electrolyte membrane. Journal of Membrane Science, 185, 83-94.

[22] Staiti, P, A. S. Arico', V. Baglio, F. Lufrano, E. Passalacqua, V. Antonucci (2001). Hybrid Nafion-silica membranes doped with heteropolyacids for application in direct methanol fuel cells. Solid State Ion 2001, 145, 101-107.

[23] Bebin, P, M. Caravanier, and H. Galiano (2005). Nafion/Clay $-\mathrm{SO}_{3} \mathrm{H}$ membrane for proton exchange membrane fuel cell application. Journal of Membrane Source, 278, 35- 42.
[24] Idibie, C. A (2017). Reaction Mechanism and Kinetics of Sulphonated Polyisoprene Elastomer for Proton Exchange Membrane. Journal of Chemical Engineering and process Techniques, 3(2), 1041.

[25] Idibie, C. A (2017). Properties of Sulphonated Polyisoprene Elastomer for Possible Proton Exchange Membrane Fuel Cell. Journal of Chemical Society of Nigeria, 42(2), 76-80.

[26] Sageetha, D (2005). Conductivity and solvent uptake of proton exchange membrane based on polystyrene(ethelenebutadiene)polystyrene triblock polymer. European polymer Journal, 4, 2644-2652

[27] Parnian, M. J, F. Gashoul, and S. Rowshanzamir (2016). Studies on the SPEEK membrane with low degree of sulfonation as a stable proton exchange membrane for fuel cell applications. Iranian Journal of Hydrogen and Fuel Cell 3(3), 221-232.

[28] Sayadi, P, S. Rowshanzamir and M. J. Parnian (2016). Study of hydrogen crossover and proton conductivity of selfhumidifying nanocomposite proton exchange membrane based on sulfonated poly (ether ether ketone). Energy, 94, 292-303.

[29] Shen, M. S. Roy, J. W. Kuhlmann, K. Scott, K. Lovell, and J. A. Horsfall, (2005). Grafted polymer electrolyte membrane fir direct methanol fuel cells. Journal of Membrane Science, 251, 121-130. 